\title{
Ahilik Sisteminde Ahlak Temelli Çalışma İlişkileri ve Günümüz Bakış Açısından Değerlendirilmesi
}

Ahmet ÜNSÜR ${ }^{1}$

Özet

Günümüz çalışma hayatında; yaşanan sorunlar artarak devam etmekte, başta devlet olmak üzere işçi ve işveren tarafları, yaşanan sorunları gidermeye yönelik birtakım tedbirler almaya çabalamaktadırlar. Organizasyonlarda yaşanan sorunlar iç ve dış paydaşlarla ilişkileri zedelemekte, bu da örgütsel ve bireysel amaç ve hedeflere ulaşma performansını olumsuz etkilemekte, önemli riskleri beraberinde getirmektedir.

Ahilik sistemi; istihdam politikaları, çalışma ilişkileri, yönetim, üretim, rekabet, paydaş ilişkileri, yöneltme-kariyer, eğitim ve geliştirme vb. alanlarda ortaya koyduğu ahlak ve insan-değer temelli çalışma ilişkileri anlayışı ile günümüz çalışma hayatı sorunlarına çözüm için değerlendirilebilecek/ uyarlanabilecek bir model olarak karşımızda durmaktadır. Bu çalışmada; ahilik sistemi, iş ahlakı boyutuyla ele alınmaktadır.

Anahtar kelimeler: Ahilik, iş ahlakı, çalışma hayatı, çalışma ilişkileri

\section{Ethics-Based Work Relations in the Ahilik System and Being Evaluated from Today's Point of View}

\begin{abstract}
In today's working life the problems that are experienced continue to increase workers, employers and especially the state are struggling to take some measures to deal with these problems. The problems experienced in organizations damage the relations with internal and external stakeholders which negatively affects the performance for achieving organizational and individual goals and targets and brings important risks with them.

Ahilik system; with a moral and human-value based work life approach in employment policies,work relationships, management, production, competition, stakeholder relations, orientation-career, training and development areas stand as a model that can be evaluated/adapted for solution to today's worklife related problems. In this study, the Ahilik system is handled in terms of business ethics.
\end{abstract}

Key words: Ahilik, business ethic, working life, work relationships

\section{Giriş}

Ahlak; Arapça 'hulk' kelimesinden türetilmiş, huy, seciye... anlamına gelen bir kelimedir. İngilizcede 'ethic', Fransizcada 'moral' kelimeleri benzer anlamda kullanılmaktadır. İyi, güzel, faydalı... ile kötü, çirkin, zararlı... gibi zit fiillerin birbirinden ayırt edilmesini sağlayan değerler kümesidir (Bikun, 2004: 12).

Ahlak ilmi; nazari (teorik) ve pratik olmak üzere çift boyutludur. Konusu insan karakteri, iyi ile kötünün tespiti, iyiyi alıp kötüden kaçınmanın yolları, vazifeler.. den ibarettir (Kandemir, 1979: 30).

\footnotetext{
${ }^{1}$ Yrd. Doç. Dr., İstanbul 29 Mayıs Üniversitesi, İ̈BF, Sosyal Hizmet Bölümü, aunsur@29mayis.edu.tr
} 
Yalova Sosyal Bilimler Dergisi

İş ahlakı genel ahlak prensiplerinin çalışma hayatına uyarlanmasıdır. Muhtelif yazarlar bu konuda birbirine yakın çok sayıda tanımlamalar yapmışlardır. Örneğin; iş ahlakı, iş dünyasında geçerli olan doğru ve yanlışları tanımlar; geliştirilecek ilişkilerde tüm paydaşlara karşı saygılı, çevreye duyarlı olmayı, iş yerinde ve dışında, adalet ve hakkaniyet ölçüsünde davranmayı, dürüst ve doğru olmayı kapsar (Mc.Hugh, 1992: 11). Bu ve benzeri tanımlamalar ele alındığında, iş ahlakının temel prensipleri; dürüstlük, adalet, ahde vefa, hakça davranma, güven, sayg1, çevre bilinci, sorumlu davranma, merhamet vb. ilkelerden oluştuğu görülmektedir. $\mathrm{Bu}$ ve bunlara ilave edilebilecek diğer temel ahlak ilkeleri iş yerlerinde aktif duruma geçirildiğinde; çalışma hayatı huzurlu, çalışanlarda sorumluluk bilincinin üst düzeyde olduğu, çalışanlar ve yönetim/yönetim temsilcileri arası güçlü ilişkilerin kurulduğu, çatışmaların olmadığı, işin ve işyerinin sahiplenildiği, biz kültürünün oluştuğu... ideal bir ortam haline dönüşecek; bu da işletmelere hedeflere ulaşma başarısı, etkinlik ve verimlilik, rekabet üstünlügü̈.. gibi avantajlar sağlayacaktır. Aynı zamanda ahlaki değerler, işletmeler için olumsuzluklara karşı koruyucu bir kalkan hüviyeti de taşıyacaktır. Günümüz çalışma hayatında yaşanan sorunlar göz önünde bulundurulduğunda, ahlak ilkelerinin mevcut sorunları çözmede ne kadar önemli bir yere sahip olduğu/ olabileceği açıkça görülmektedir. $\mathrm{Bu}$ çalışmada; yüzyıllarca, ahlakla işi bütünleştirerek başarıyla uygulamış bir sistem olan 'Ahilik' konusu, çalışma ilişkileri ve iş ahlakı boyutuyla ele alınmaktadır.

\section{Ahilik Sistemi ve Gelişimi}

Ahi; Arapçada 'kardeş, kardeşim' anlamında kullanılan bir kelimedir. Türkçede ise 'Akı', 'cömert' anlamında kullanılan bir kelime vardır ki; ahiliğin bu kökenden geldiğini ileri sürenler de bulunmaktadır (TDV İslam Ansiklopedisi, 1998: 540). Örgütsel bir kavram olarak ise; 13.yüz yıldan itibaren Anadolu esnaf ve sanatkâr kuruluşlarının iş gücü yetiştirme, işleyiş ve kontrollerini düzenleyen bir sistem olarak ifade edilebilir (Çağatay, 1997:1). O halde; Ahiliği, kardeşlik ilişkisinde gerek kan bağ 1 , gerekse din kardeşliği- 'Mü'minler ancak kardeştirler (K.Kerim, Hucurat: 10) olduğu gibi, dışarıdan herhangi bir zorlama olmaksızın, güçlü bağlarla donanmış, ilişkileri sağlam temeller (Değerler) üzerine kurulu bir ilişkiler sistemi olarak değerlendirmek mümkündür.

Ahilik sisteminin temelini, Fütüvvet Teşkilatı'nın oluşturduğu görülmektedir. Mensuplarına; civanmert, ayyar, feta denilen bu kuruluşun, İslam'ın ilk dönemlerinden itibaren filizlendiği, ancak H.3. asırdan itibaren sistematik bir hüviyete büründüğü görülmektedir (Ünsür, 1998, 545).

Fütüvvet teşkilatları Abbasi Halifesi Nasır Li Dinillah (1180-1225) döneminde devlet desteği ile güçlenmiş, diğer Müslüman toplumlara yayılması için çabalar sarfedilmiş, I. Gıyaseddin Keyhüsrev zamanında Anadolu Selçuklu Devleti ile temaslar kurulmuş, bu kapsamda; Evhadüddin Kirmani, Muhiddin İbn-i Arabi, Şeyh Nasruddin Ebu-1 Hakayık Mahmud b.AhmedEl Hoyi-Ahi Evran (1171-1261) Anadolu'ya gönderilmiştir. Bu dönemde; Evhadüddin Kirmani ve halifeleri için çok sayıda tekke ve zaviye yapılmış, bilahare I.İzzettin Keykavus ve I. Alaaddin 
Yalova Sosyal Bilimler Dergisi

Keykubat fütüvvet teşkilatına kaydolmuşlardır (TDV İslam Ansiklopedisi, 1998: 540).

Fütüvvet sisteminin 'kılıç (askerlik/cihad) ve irfanı (erdem/eğitim)' ön plana çıkardığ 1 görülmektedir. Fütüvvet temelli bir sistem olan ahilik, Anadolu'da, özellikle I. Alaaddin Keykubat (1220-1237) döneminde, Ahi Evran öncülüğünde, şehir, kasaba ve köylerde yaygınlaşmış, siyasi, sosyal, kültürel ve iktisadi hayata damgasinı vurmuştur.

Ahilik sistemi Osmanlı Devleti'nin kuruluşu ve yeniçeri askeri teşkilatının oluşumunda da önemli rol oynamıştır. İlk Osmanlı Padişah ve vezirlerinin önemli bir bölümünün teşkilat mensubu olduğu, Sultan I. Murad (1326-1389)'ın şed kuşandığ1, Şeyh Edebali'nin ahi şeyhlerinden olduğu, Orhan Gazi'nin bir ahi unvanı olan 'İhtiyaruddin' unvanına sahip olduğu bilinmektedir (TDV İslam Ansiklopedisi, 1988: 541).

Ahi Evran, 1206 yılında Kayseri'ye yerleşmiş ve kendisine ait 'Debbağ Atölyesi' kurmuştur. Anadolu'daki kendisine ait ilk debbăg atölyesini önce Konya'da kurmuş, daha sonra Kayseri'ye nakletmiştir (Ahilik Ansiklopedisi, 2014: 86). Bu nedenle kendisi debbağlık (Dericilik/Deri tabaklama) mesleğinin piri olarak bilinmektedir.

13-20.yüzyıl arasında 'Anadolu Esnaf ve Sanatkârlar Birliği' olarak faaliyet gösteren ahilik; 'güzel ahlak, misafirperverlik ve sanatın bir bileşimi' olarak karşımıza çıkmaktadır. Ahi Birliklerinin dört temel gruba ayrıldığı görülmektedir. Bunlar; a) Ahiyan-1 Rum (Esnaf örgütlenmesi), b) Baciyan-1 Rum (Kadın örgütlenmesi), c) Gaziyan-1 Rum (Savaşç1/Gaziler), d) Abdalan-1 Rum (Gezginler). Ahilik Sisteminin Anadolu'da kurucu lideri konumunda bulunan Ahi Evran'la ilgili olarak dönemin şairlerinden Gülşehri şunları söylemektedir;

Kişinin endişesün bilür idi

Hacetin dahi reva k1lur idi

Sofra dökmeğ ile haş idi başı

Zede pirinç, ak pirinç idi aşı

Sofraya halkı üşüren ol idi

El ile helva bişüren ol idi

Şimdi göğ altında bir er yok durur

Ancılayın kapusu açuk durur (Tarım, 1948: 83).

Ahi ahlakının temel prensipleri, Ahi Şecerenameleri ve Fütüvvetnamelerde belirtilmiştir. Günümüzde, bilgi edinmek için başvurulan Ahi Fütüvvetnamelerinden bazıları şunlardır;

$\checkmark$ Sühreverdi Fütüvvetnamesi (Kitabu-1 Fütüvve, Risale el Fütüvve)

$\checkmark$ Sufi Fütüvvetnameleri (Kuşeyri Risalesi..)

$\checkmark$ Çobanoğlu Fütüvvetnamesi (Yahya b.Halil Çoban el Burgazi)

$\checkmark$ Radavi Fütüvvetnamesi (Seyyid Hüseyin b.es Seyyid Alaeddin el Hüseyni el Radavi, 'Miftahu-d Dekaik fi Beyan el Fütüvve ve-1 Hakaik') 
Yalova Sosyal Bilimler Dergisi

Ahilik ahlak ilkelerinin yer aldığı fütüvvetnameler incelendiğinde, İslam ahlakının temel değerlerinden beslendiği açıkça görülmektedir. Fütüvvetnamelerde yer alan ilkelerin tamamı 740 tanedir. Sisteme ilk defa dâhil olanlara bunlardan önceliklendirilmiş olan, en az 124 tanesini bilmesi ve içselleștirmiş olması istenmektedir. Ahlaki yeterliliğin, çalışma hayatına başlayabilmek için ön şart olarak belirlendiği görülmektedir (Çağatay, 1997: 163). Ahilikte ahlak eğitimi; hem işyerlerinde, hem de zaviyelerde/yaren evlerinde yapılmakta ve süreklilik arz eden bir niteliğe sahipti.

İş yerleri genellikle eğitim kurumları (medreseler) yakınında olması, meslek eğitiminin yanında, ilave ahlak eğitimi imkânı da oluşturmakta idi (Tabakoğlu, tarih, 250). Çıraklık ve kalfalık döneminde genç, iş yerinde ustası tarafından 'uygulamalı ahlak eğitimi'ne tabi tutulmakta idi (Ünsür, 1988: 547).

Ahilikte el, sofra ve kapının (cömertlik, misafirperverlik..) hep açık; göz, bel ve dilin (harama meyletme, ihtiras...) hep kapalı olması genel ilke olarak benimsenmiştir. Bu konu ile ilgili olarak Gülşehri;

Alt1 şartı var fütüvvet yolunun

Üçü açık, üçü kapaludur anın

İşit imdi iş bu sözü sıdk ile

Kim bilindi işbu mani nakl ile

Kapusu ve eli ve sofra bağ

Ol kim üçü kapaludur, evvel dili

Gözü dahi bağlı durur bili

İş bu altı hasiyet kim var idi

Ahi yanında kamusu yar idi (Çağatay, ty: 13).

Ahilikle ilgili ayrıntılı bilgileri; özellikle ahi şeyhlerinin eserleri, İbn-i Batuta ve Evliya Çelebi Seyahatnamelerinden öğrenmekteyiz. İbn-i Batuta ahiler için; 'dünyada bunlardan daha iyi kalpli, iyi davranışlı kişiye rastlamadım' demektedir (Esnaf ve Sanatkâr, 1973: 33).

\section{Ahi Fütüvvetnamelerinde Belirtilen Temel Ahlak İlkeler}

- Yaradana itaat, iyi bir kul olma: Kuşeyri Risalesinde; onlar-ahiler rablerine iman etmiş gençler idiler' denilmektedir (Esnaf ve Sanatkar, 1973: 5).

- Nefisle mücadele, nefse hakimiyet (Sufi konsept): Sühreverdi (Ebu Hafs Ömer), fütüvvetin tasavvufun bir parçası olduğunu ifade etmektedir (Esnaf ve Sanatkar, 1973: 8)

- Misafirperverlik: Misafirlere özel ihtimam gösterilir, ayrılışlarında at, elbise, para vb. değerli hediyeler verilir, misafir kabulü ve ikram konusunda birbirleriyle yarışırlardı (İbn-i Batuta Seyahatnamesi, s.329). 
Yalova Sosyal Bilimler Dergisi

- Doğruluk, dürüstlük, helal kazanç: Hiç kimse kendi el emeği (alın teri) ile kazandığından daha hayırlı bir lokma yememiştir (Buhari, Büyü, 15 /2013:35)

- Kendi ihtiyacı varken elindekini başkasına verme (İsar-Diğergamlık): Seyyid Şerif Cürcani 'Tarifat' adlı eserinde; 'Fütüvvet, halkı dünya ve ahirette kendi nefsine yeğ görmektir' demektedir. Cüneyd-i Bağdadi ise; Fütüvvet, kulun kendi nefsini başkasınınkinden üstün ve değerli görmemesidir' ifadesini kullanmaktadır (Risale-i Kuşeyriye, 1940: 180-184).

- Adab-ı muaşarat kurallarına uyma: .(Anadol, 1991: 14). Belirtilen ahlaki kurallara aykırı davrananların sistemden ihraç edilecekleri belirtilmektedir (Çağatay, ty: 19).

- Ayırımcılık yapmaksızın insanları sevme, yardımcı olma (Güllülü, 1997: 92-93)

- Yine aynı kaynaklarda yer aldığı üzere herkese iyilik yapma, kendini insanlığa vakfetme; cömertlik; vefa; nasihat, kötülükten alıkoyma, eğitme (işyeri,zaviyeler,yaren odaları..); tövbe (hatadan dönme..); gücü varken affetme; hiddetli iken yumuşak davranma; kudreti varken tevazu; düşmanlığı dostlukla, kötülüğü iyilikle karşılama; ihtiyaç sahibine minnetsiz ihsan; iş ve meslek sahibi olma; iddihardan kaçınma (18 dirhem'den fazla gümüş biriktirmeme); bey, devlet kapısından uzak durma; edeb ve haya; yalan söylememe; dedikodu ve iftiradan kaçınma; hile yapmama, aldatmama (bizi aldatan bizden değildir..); hak ve adalete riayet etme; zulme ve zalime karşı koyma; zayıfın hakkını, haksız güçlüden almaya yardımcı olma da belirtilen ahlak ilkeleri arasında yer almaktadır.

\section{Ahilik’te Çalışma İlişkilerinin Temel Özellikleri}

Ahilik, sanat ya da meslekleri için gerekli hammadde tedarikinden, onun işleniş̧i ve satışına kadar her hususu ayrıntılarıyla kurala, standarda bağlamıştır. Bu durum ortaya çıkabilecek çatışmaları engellemiştir. Örneğin; 'Aşçının pişirdiği et çiğ olmaya, tuzsuz olmaya, kasesi ve bezi temiz ola, kazanı kalaysız olmaya, çanakları eski ve sırçasız olmaya..' denilmiştir (Esnaf ve Sanatkar, 1973: 37-41). İslam ahlakının temel değerleri üzerine inşa edilmiş olan ahilik sistemi; uhuvvet (kardeşlik, diğergamlık..) temelli anlayışını, çalışma ortamı ve çalışma hayatı dışında hassasiyetle uygulamış, başarısını buna bağlı olarak uzun yıllar boyunca 'başarılı bir model 'olarak sürdürmüştür.

Ahi Evran'ın Selçuklu Sultanı II. İzzettin Keykavus'a sunduğu 'Letaif-i Hikme' adlı kitap, sultanlara ve yöneticilere nasihat verici ve "Siyasetname" türü bir eserdir. Bu eserde halkın ihtiyaçları belirlenmekte, bu ihtiyaçların karşılanması, istihdamın, kaliteli, bol ve ucuz üretimin yapılması esnasında ortaya çıkabilecek sorunlara karşı tedbirlerin neler olması gerektiği şöyle anlatılmaktadır;

\footnotetext{
"Allah insanı, medenî tabiatlı yaratmıştır. Bunun açıklaması şudur: Allah insanları yemek, içmek, giyinmek, evlenmek, mesken edinmek gibi çok şeylere muhtaç olarak yaratmıştır. Hiç kimse kendi başına bu ihtiyaçları karşılayamaz. Bu yüzden demircilik, marangozluk, dericilik gibi çeşitli meslekleri yürütmek için çok insan
} 
Yalova Sosyal Bilimler Dergisi

gerekli olduğu gibi, bu meslek dallarının gerektirdiği âlet ve edevatı imal etmek için de birçok insan gücüne ihtiyaç vardır. $\mathrm{Bu}$ yüzden toplumun ihtiyaç duyduğu ürünlerinin üretimi için lüzumlu olan bütün sanat kollarının yaşatılması şarttır. Bununla da kalmayıp, insanların sonradan doğacak ihtiyaçlarını karşılamak için yeni sanat dallarının meydana getirilmesi gerekmektedir" (esnaf.gtb.gov.tr).

Ahi Evran'a göre; toplumdaki fertlerin büyük bir kesiminin sanata yönlendirilmesi ve her birinin belli bir sanat dalıyla meşgul olması gerekir ki, toplumun ihtiyaçları görülsün. Ahi Evran'ın kurduğu Ahilik Teşkilâtının eğitim anlayışı bu temel görüşe dayanmaktadır. Devlete düşen görev, bu görüşe destek vererek halkın eğitilmesine ve yönlendirilmesine yardımcı olmaktır. Ahi Evran'ın eserinde belirttiği eğitim ve öğretim konusundaki tüm öneriler, Ahi birliklerinde uygulanmıştır. Ahi Evran'ın mesleki teknik öğretim ve ahlâka yönelik eserleri, y1llarca Ahi birliklerinde ders kitabı olarak okutulmuştur.

$\mathrm{Bu}$ bilgiler 1şığında 'ahilik çalı̧̧ma ilişkileri'nin temel özellikleri şöylece belirlenebilir: Dengeli bakış açısı, dünya-ahiret dengesi (Hiç ölmeyecekmiş gibi dünya için, yarın ölecekmiş gibi ahirete, hesaba hazırlıklı olma..); enformel ilişkiler (Baba-evlat,abi-kardeş,yönlendirme,destekleme, eğitme,koruma-kollama..); etkin meslek/sanat eğitimi/öğrenme..; paydaşlarla güçlü, güven odaklı ilişkiler; performans, ahlak, davranış, işe ve işyerine bağlılık odaklı kariyer sistemi; işi ve mesleği ile bütünleșme, gönülden bağlanma; ișyeri ve işyerleri arası dayanışma; özveri; kanaatkarlık (gözü tok olma); meslek ve sanatının pirlerini örnek alma; yeteneklere ve yetkinliklere uygun iş,liyakat; sürekli eğitim (işbaşı, iş dış1; zaviyeler, yaren evleri..).

\section{Ahilik Sisteminde Bazı İnsan Kaynakları Yönetimi Yaklaşımları}

\section{1. İşe Alma-Seçme ve Yerleştirme}

10 yaşına kadar olan çocuklar, velisi tarafindan istidad1-yetenekleri göz önünde bulundurularak bir usta yanına bir meslek öğrenmesi amacıyla verilir, bunlar iş yerlerinde mesleki eğitim görürken zaviyelerde ahlak eğitimi almakta idiler (Ekinci, 2008: 152).

\subsection{Eğitim ve Geliştirme}

Ahilik sisteminde eğitim (mesleki ve ahlaki) süreklilik arz eden bir durumdur. İş başı eğitimler uygulamalı olarak iş yerinde, genel ve ahlaki eğitimler medrese ve zaviyelerde yürütülmektedir. Usta bütün beceri ve hünerlerini zamana dayalı olarak kalfa ve çıraklarına aktarmakta, onlara bu konuda rehberlik etmektedir.

\subsection{Performans Değerlendirme}

Terfi (kalfa, usta) ve dükkân açma işlemleri performansa dayalı olarak yürütülmüştür. Performans parametrelerini ahlaki değerler ve iş verimi oluşturmaktadır. Genel ahlak kuralları ile çalışma ahlakı kurallarını ihlal edenler cezalandırılır, gerekli hallerde meslekten ihraç edilirdi. Pabucu dama atma uygulaması bu konuda bir örnek'tir. Ahilik sisteminde, ham maddenin tedarikinden 
Yalova Sosyal Bilimler Dergisi

onun üretimi ve satışına kadar bütün sürecin belirlenen kurallar dâhilinde yönetildiği görülmektedir (Esnaf ve Sanatkar, 1973: 37). Bu durum, hem kurumsal performans açısından hem de paydaş ilişkileri yönetimi açısından performansın üst düzeye yükselmesine neden olmuştur.

\subsection{Kariyer Sistemi}

Ahilik çalışma siteminde; kariyer yolu dört basamaklı olarak tasarlanmıştır. İlerleme için parametreler belirlenmiştir. Bunların başlıcaları aidiyet (işi ve iş yerini sevme), kıdem, performans, davranış, kalite, müşteri odaklılık.. gibi unsurlardır. Usta ve kalfaların (yöneticiler) yamak ve çıraklara kariyer danışmanlığı yaptıkları görülmektedir.

\subsection{Ahilikte kariyer basamakları ve temel yetkinlikler;}

$\checkmark$ Yamak (10 yaşından küçükler, yetenek belirleme, gözlem dönemi)

$\checkmark$ Çırak (En az 2 yıl başarıyla yamaklık yapmış olma)

$\checkmark$ Kalfa (En az 3 yıl başarıyla çıraklık yapmış olma)

$\checkmark$ Usta/Üstad (En az 3 yıl başarı ile kalfalık yapmış olma, sanatına bağlılık, astlarını yetiştirme beceri ve başarısı, hakkında hiç şikayet bulunmaması, müşteri ve çalışanlara karşı tutumu, işyeri açabilmek için finansal yeterlilik..)

\section{Ahilik İş Ahlakı'nın Temel Nitelikleri}

İş ve meslek sahibi olma (Zorunlu haller dışında; işsizlik ve tembellik ahlaksızlık olarak nitelendirilmektedir).

$\checkmark$ Helal kazanç (Hiç kimse el emeğinden daha hayırlı lokma yememiştir).

$\checkmark$ İş yeri huzurlu bir ortamdır (Stres, çatışma..vb. olumsuzluklardan arınmış..).

$\checkmark$ İnsani çalışma ilişkileri (menfaat birliği..).

$\checkmark$ İş bölümü ve uzmanlaşma (Mesleki iş bölümü, uzmanlaşma..).

$\checkmark$ Doğruluk, dürüstlük, güven esaslı bireysel, sosyal, ekonomik ilişkiler.

$\checkmark$ Disiplinli çalışma (İş ve işyeri disiplini..).

$\checkmark$ Dayanışma, diğergamlık (Biz kültürü..), orta sandığı (Esnaf dayanışması..).

$\checkmark$ Standartlara uygun, kaliteli üretim (Patent hakkı, iş yeri açma yeterliliği, vasıflı işçilik, müşteri odaklılık.. Gerektiğinde cezalandırma; pabucu dama atılma, meslekten ihraç..).

$\checkmark$ Kalite ve fiyat kontrolü (İç denetim, diş denetim, esnaf kethudalığı..).

$\checkmark$ İhtiyaca göre üretim (Kaynakları etkin kullanma, israf etmeme..).

$\checkmark$ Tüketiciyi koruma (Uygun fiyat, ürünü iade imkanı, doğrudan/aracısız satış..).

$\checkmark$ Kalite ve müşteri memnuniyeti haricinde rekabetin olmaması (Hayır ve iyilikte dayanışma ve yarışma..).

$\checkmark$ Güçlü paydaş ilişkileri (İç ve dış paydaşlar arası...). 
Yalova Sosyal Bilimler Dergisi

\section{Ahilik İş Ahlakının Günümüz Çalışma Hayatı Açısından Önemi}

Memleketler parasızlıktan değil, ahlaksızlıktan çökerler (Çiçero).

İş ahlakının temelinde insan, dolayısıyla insan emeği vardır. Günümüz çalışma hayatı ahlaki sorunlarının temelinde, ahlaki değerleri göz ardı eden kapitalist seküler sistem bulunmaktadır. Bu nedenle, çalışma ilişkileri ahlaki esaslara dayandırılmalıdır (Tabakoğlu, 2009: 272). Sanayi inkılâbı sonrası çalışma hayatında ortaya çıkan ahlaki sorunların, kapitalizm ve küreselleşmenin de etkisiyle telafisi zor boyutlara ulaştığı görülmektedir.

Ahiliğin 'çıkar birliği/ortak menfaat' ilkesine karşın kapitalizmin 'çıkar odaklı'/bencil anlayışı, çalışma ilişkileri ve paydaş ilişkileri'ni çatışmacı bir zemine taşımaktadır. Bu nedenle; başta çalışma hayatı olmak üzere, hayatın tüm alanlarında ortaya çıkan çıkar çatışmaları, kişiler/kurum-kuruluşlar arası güven kaybına neden olmuş, bu durum iş sonuçlarına(üretim, müşteri mutluluğu vb.) da yansımıştır.

Mevcut durum, önleyici niteliği ile ahlaki değerlerin önemini bir kez daha ortaya koymaktadır. Bu nedenle; ortaya çıkan güvensizliği ortadan kaldırmak/azaltmak amacıyla; son yıllarda işletmelerin ahlak bildirgeleri (etik kod) ve etik kurulları oluşturmaya başladığı, bu bildirgelerde tüm paydaşlarla ilişkilerini ahlaki temeller üzerinde kurgulama çabası içine girdiği, bu husustaki taahhütlerini tüm paydaşlarına deklere etmeye, bu suretle kaybolan paydaş güven ve mutluluğunu yeniden kazanma gayretine yöneldiği görülmektedir.

Kurum/Kuruluşlar; paydaş (iç ve dış) güveni oluşturmaya yönelik yönetim ve geri bildirim yaklaşımları ile sistemi sürekli iyileştirme, bu suretle paydaş mutluluğu'nu yakalamayı hedeflemektedirler.

Çalışmada ortaya konulan Ahilik sisteminin genel ahlak ve çalışma ahlakına yönelik prensip ve yaklaşımları, günümüz çalışma hayatı'nın temel sorunlarının çözümünde göz önünde bulundurulduğunda, mutlak çözümcül etkisinden söz edebiliriz.

Ahlak prensiplerini evrensel bir din olan İslam'dan alan Ahilik ahlakı, halkının büyük çoğunluğu Müslüman olan Türkiye'de, iktisadi ve sosyal hayatın bütününde uygulanmak (unutulmaya yüz tutmuş bir takım örf ve adetlerin yeniden canlandırılarak) suretiyle, yaşanan ahlak temelli sorunları aşmak mümkün olabilecektir.

\section{Sonuç}

Görüldüğ̈̈ gibi; Ahilik Sisteminin hayatın muhtelif alanları ve çalışma hayatı ile ilgili olarak ortaya koyduğu temel değerler, evrensel nitelikler taşımaktadır ve sorunları önleme/sorun çözme aracı olarak karşımızda durmaktadır. Ahilik sisteminin, temel insan kaynakları yönetimi süreçleri olan; işe alım, eğitim, kariyer, performans, motivasyon, kalite $v b$. alanlarda olduğu gibi iç ve dış paydaş 
Yalova Sosyal Bilimler Dergisi

ilişkilerinin yönetiminde de kişi ve kurum/kuruluşlar açısından çözümcül yaklaşımlar ortaya koyan bir niteliğe sahip olduğu, hem teorik olarak hem de uygulama örneklerinden anlaşılmaktadır.

Günümüzün en temel çalışma hayatı sorunlarından ayırımcılık, bencillik, güvensizlik, aldatma, ikiyüzlülük, taciz-yıldırma, iletişimsizlik, sorumsuzluk, disiplinsizlik, çatışmacılık, uyumsuzluk... gibi hususların yaşanan sorunların temelini oluşturduğu, bu sorunların işletme hedefleri başta olmak üzere toplumsal hedeflere ulaşmada temel engel teşkil ettiği, kaynakların özellikle de insan kaynağının kullanımında ciddi problemlere yol açtığı görülmektedir.

$\mathrm{Bu}$ nedenle çalışma hayatı ve sosyal hayatın amacına uygun yaşanabilmesi ve etkinliği için Ahilik Sistemi; yönetim, ahlak, eğitim (genel, mesleki), kalite, davranış..vb. yönleriyle başta merkezi ve yerel yönetimler, kamu/özel işletmeler olmak üzere, tüm yönetim birimlerince durumsallık ilkesi göz önünde bulundurulmak suretiyle, yönetim ve ilgili alanlara uyarlanabilecek bir model olarak değerlendirilmelidir.

\section{Kaynakça}

Anadol Cemal, (1991), Türk İslam Medeniyetinde Ahilik Kültürü ve Fütüvvetnameler, Kültür Bakanlığı, Ankara.

Bikun Refik İsa, (2004), İş Ahlakı, Çev.A.Yaşar. İGİAD, İstanbul.

Çağatay Neşet, (1997), Bir Türk Kurumu Olan Ahilik, TTK, Ankara.

Çağatay Neşet, (ty), Ahlakla Sanatın Bütünleştiği Türk Kurumu Ahilik Nedir, Ankara Esnaf ve Sanatkarlar Konfederasyonu, Ankara.

DİB, (2013), Hadislerle İslam (7 Cilt), Ankara.

Ekinci Yusuf, (2008), Ahilik, Özgün Matbaac1lık, Ankara.

Esnaf ve Sanatkârları Konfederasyonu, (1973), Cumhuriyetin 50.Yılında Esnaf ve Sanatkâr, Ankara.

Güllülü Sabahattin, (1977), Ahi Birlikleri, Ötüken Yayınevi, İstanbul.

Gümrük ve Ticaret Bakanlığı, (2014), Ahilik Ansiklopedisi, Ankara.

Gümrük ve Ticaret Bakanlığı, Esnaf ve Sanatkarlar Genel Müdürlügü, esnaf.gtb.gov.tr

İbn-i Batuta Seyahatnamesi, M. Şerif Tercümesi, İstanbul,1315-1319

Kandemir M.Yaşar, (1979), İslam Ahlakı (Örneklerle), Nesil Yayınları, İstanbul.

Kuşeyri Abdülkerim, (1940), Risale-i Kuşeyriye, İstanbul

Mc Hugh Francis P., (1992), Ethics In Busıness Now, (TÜSİAD), İstanbul.

Tabakoğlu Ahmet, (2009), “Türkiye'de İş Ahlakı Geleneği”, İşletmelerde İş Etiği, İTO, İstanbul.

Tarım Cevat Hakkı, (1948), Tarihte Kırşehri-Gülşehri, Yeniçağ Matbaası, İstanbul

TDV İslam Ansiklopedisi, (1988), C.1, Ahilik Maddesi, İstanbul

TESK, (1973), Cumhuriyetin 50.Yılında Esnaf ve Sanatkâr, Ankara.

Ünsür Ahmet, (1998), “Geleneksel Türk Kültüründe İs Ahlakl ve Sosyal Sorumluluk”, Siyasette ve Yönetimde Etik, Sakarya Ü.-Adapazarı Tic.ve Sanayi Odası, Adapazarı. 